\title{
3D printing set to revolutionize medicine
}

\author{
Cite as: CMAJ 2017 July 24;189:E973-4. doi: 10.1503/cmaj.1095442
}

Posted on cmajnews.com on July 4, 2017.

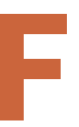

ull-size three-dimensional models of complex tumours, replacement joints that grow real bone, and replacement "skin" to help burns heal are among the Canadian innovations that are here or coming soon through 3D-printing technology.

"I'm not sure we've appreciated its full potential," said Dr. Rita Kandel, chief of pathology and laboratory medicine at Mount Sinai Hospital in Toronto, who calls herself a "tissue engineer." She says the technology will play a critical role in education and simulation, as well as design of orthopedic implants and other complex structures.

While it's called "3D printing," in most cases the technology does not involve ink or toner, but a wide variety of materials such as plastics, metals, ceramics and fluids. The material is extruded, usually from a small nozzle, building up layers to produce 3D objects, a process also called additive manufacturing, rapid prototyping or solid freeform technology.

3D printing is already helping surgeons operate on complex bone tumours at the Ottawa Hospital, said Dr. Adnan Sheikh, the hospital's director of advanced musculoskeletal interventions. From the computed tomographic or magnetic resonance imaging scans, a 3D-image file is created and sent to a specialized 3D printer. The device can create a full-size model of a bone tumour that has invaded the joint or vasculature, showing the tumour, bone, and vasculature in different colours. Surgeons use these models for presurgical planning, or bring them right into the operating room to consult during surgery.

"The surgeons like the models because it gives them a different perspective," said Sheikh. "You can hold them and place them in the same position as they will be during the surgery." Future uses include

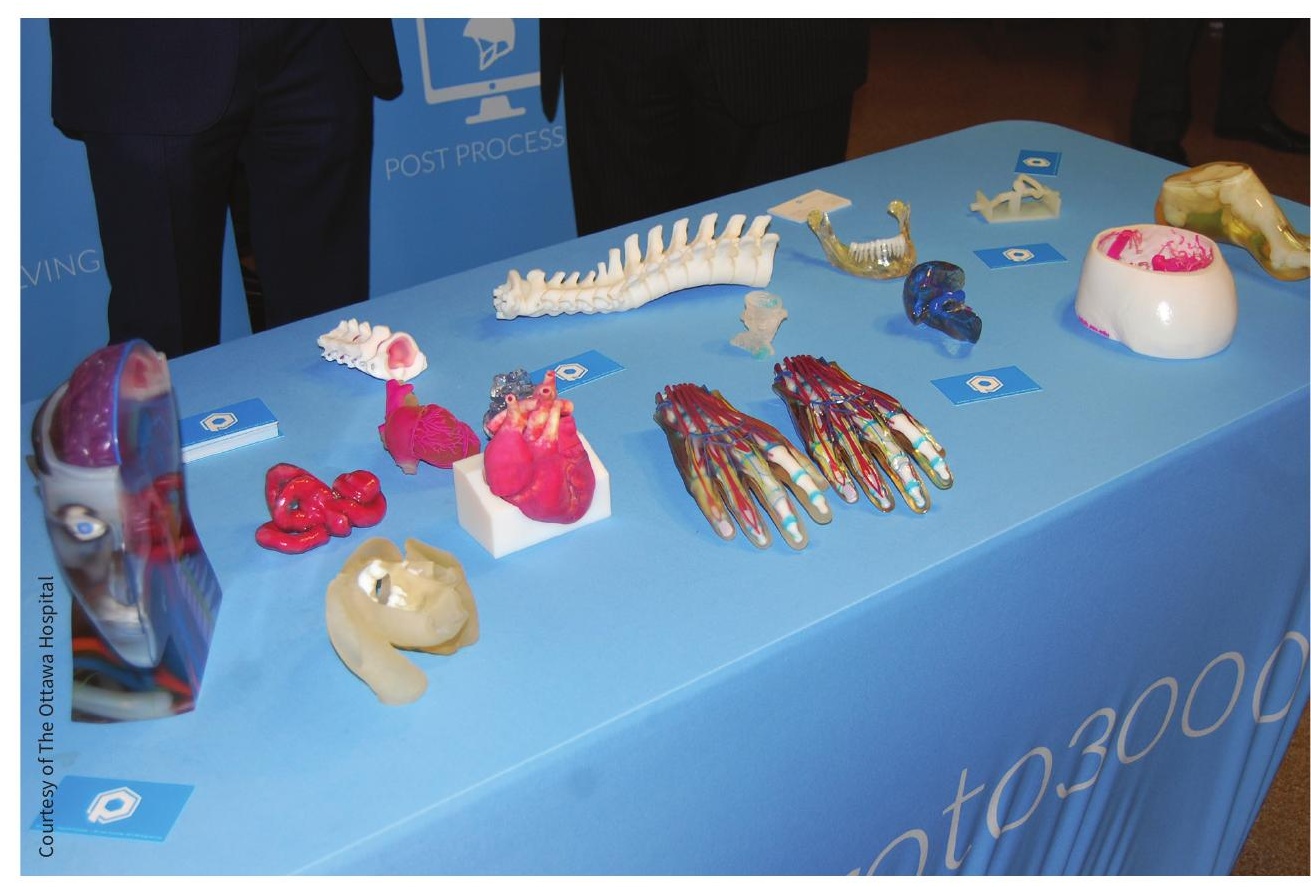

3D models, like these from The Ottawa Hospital, are used to replicate tumours and for other surgical applications.

models for heart-valve replacement surgery, he added. The University of Ottawa's medical school is also using 3D-printed models of anatomy and pathology, which improves students' understanding of the structures, said Sheikh.

At Mount Sinai Hospital, Kandel is using $3 \mathrm{D}$ printing to replace both bone and cartilage by creating "biological" replacement joints that move smoothly. She has used stem cells to generate cartilage, but bone was proving more difficult. The solution was to "print" a replacement bone from a porous and biodegradable material, on which new bone cells would grow, filling the material's pores. The replacement bone would slowly degrade, ultimately replaced by new bone. To date, Kandel has successfully done this in animal models, and she continues to experiment, improving this process. She said clinical trials of "an integrated cartilage-bone substitute" in humans are 5 to 10 years away.

3D printing involving human cells has made headlines for Axel Guenther, an associate professor of mechanical and industrial engineering, as well as biomaterials and biomedical engineering, at the University of Toronto. Two of his doctoral students won a James Dyson Award in 2014 for the PrintAlive Bioprinter, a specially designed printer that extrudes relatively flat, continuous layers integrating human skin cells and hydrogels, to mimic how tissues are organized, said Guenther. This can be used just like human skin for healing wounds of many kinds, he said, although the focus is on severe burns, to avoid or augment skin grafts. The device is small and light, and throughput is fast, making it ideal for clinical use.

"It's a unique, patented technology," 
explained Guenther. "It has not been done before." The printed "skin" has been tested in mouse models, and Guenther said a current challenge is scaling it up to larger animals. While he could not put a timeline on clinical trials, he said, "We're committed to developing this technology to clinical use."

All 3D-printing innovators emphasize that breakthroughs are only possible through close collaboration between medicine and engineering. Sheikh works closely with an engineering team and "makerspace" at the University of Ottawa. Kandel collaborated with colleagues at the University of Waterloo and the Univer- sity of Toronto to design a custom printer. Guenther's laboratory works closely with the burn unit at Sunnybrook Health Sciences Centre. "Things happen only when researchers from very different backgrounds get together to solve specific problems," he said.

The medical applications are expected to expand rapidly, said Sheikh. "This is still in its very early days." Internationally, 3D printing is already being used to produce customized replacement joints, implants, stents, prostheses, hearing aids and "invisible" dental braces. As well, in drug manufacturing, it is being used to reproduce complex drugs accurately and could soon allow pharmacists to print "personalized" drugs for patients with specific needs.

But "bioprinting" cells and even organs is the next big application. A US company, Organovo, has bioprinted human kidney and liver tissue, currently used to test drug toxicity, but with future potential for replacement organs. "This will change how we look at organ transplants," said Sheikh. "I'm sure in the next 10 years you have will people walking around with printed livers and kidneys."

Carolyn Brown, Ottawa, Ont. 